\section{Cureus}

\title{
Current Scenario of HIV/AIDS, Treatment Options, and Major Challenges with Compliance to Antiretroviral Therapy
}

\author{
Adnan Bashir Bhatti ${ }^{1}$, Muhammad Usman ${ }^{2}$, Venkataramana Kandi ${ }^{3}$ \\ 1. Medical Director of Clinical Research, Spine Surgery, Tristate Brain and Spine Institute, United States \\ 2. Department of Medicine, Jinnah Hospital Lahore (JHL)/Allama Iqbal Medical College (AIMC), Lahore, \\ Pakistan 3. Department of Microbiology, Prathima Institute of Medical Sciences, Karimnagar, IND
}

$\square$ Corresponding author: Adnan Bashir Bhatti, dr.adnanbashir@gmail.com Disclosures can be found in Additional Information at the end of the article

\section{Abstract}

The discovery of the human immunodeficiency virus (HIV) as the causative organism of acquired immunodeficiency syndrome (AIDS) and the inability of modern medicine to find a cure for it has placed HIV as one of the most dreaded pathogens of the $21^{\text {st }}$ century. With millions of people infected with HIV, it was once thought to result in "medical apocalypse". However, with the advent of antiretroviral therapy (ART), it is now possible to control HIV. Adherence to ART helps to keep the viral load under control and prolong the time of progression to AIDS, resulting in near normal life expectancy. Even with the introduction of ART, a substantial number of patients fail to adhere due to a variety of reasons, including adverse side effects, drug abuse, mental disorders, socioeconomic status, literacy, and social stigma. With the availability of so many options for HIV treatment at each stage of the disease progression, physicians can switch between the treatment regimens to avoid and/or minimize the adverse effects of drugs. Close monitoring, major social reforms, and adequate counselling should also be implemented to circumvent other challenges.

Categories: Infectious Disease, Allergy/Immunology, HIV/AIDS

Keywords: hiv, aids, drug adverse effects, hiv/aids, highly active antiretroviral therapy (haart), antiretroviral therapy

\section{Introduction And Background}

Acquired immunodeficiency syndrome (AIDS) is a medical condition caused by the human immunodeficiency virus (HIV). HIV infection is a very current threat and can easily be termed as a curse upon the human race. The scientific community first noticed and recognized the presence of AIDS as an actual disease following an increase in the incidence of very rare opportunistic infections and cancers among otherwise healthy homosexual men [1]. HIV-1 was identified as the causative organism soon after the first official recognition of HIV patients in the USA [2]. HIV-2 was reported first in Africa in 1985 and is markedly different from HIV1 [3]. It closely resembles a simian virus that infects macaques in captivity. Simian viruses that naturally infect African primates are suspected to reach humans via multiple cross-species transmissions resulting in the spread of HIV-1 and HIV-2 [2]. The global prevalence of HIV has expanded since its discovery and has now spread across the globe despite advances in antiretroviral treatments (ART). The mortality and morbidity rates related to HIV infections remain high in developing countries largely due to food insecurity and malnutrition [4]. Longterm concomitant sexual relationships and high infectivity during the early phase of HIV infections are other factors behind the extensive spread of HIV in the general population [5]. 


\section{Cureus}

Figure 1 summarizes the number of victims by gender, incidence, and death, as well as the latest statistical data covering the 2014 AIDS epidemic [6].

\section{Global summary of the AIDS epidemic 2014}

\author{
Number of people \\ living with HIV in 2014
}

Total 36.9 million [34.3 million -41.4 million] Adults 34.3 million [31.8 million -38.5 million] Women 17.4 million [16.1 million - 20.0 million] Children (<15 years) 2.6 million [2.4 million -2.8 million]

\section{People newly infected} with HIV in 2014

Total 2.0 million [1.9 million -2.2 million] Adults 1.8 million [1.7 million -2.0 million] Children (<15 years) 220000 [190 $000-260000]$
Total 1.2 million [980 $000-1.6$ million] Adults 1.0 million [890 $000-1.3$ million] Children (<15 years) 150000 [140 $000-170$ 000]

\section{FIGURE 1: Prevalence of HIVIAIDS as of 2014.}

Figure retrieved from WHO website on December 6, 2015 from the link: http://www.who.int/hiv/data/epi_core_july2015.png?ua=1

\section{Review}

\section{The infection}

The main site of the attack is the immune system, especially the CD4 T-lymphocytes (CD4 cells). Once infected, the virus gradually and silently overpowers the host's defense mechanisms, resulting in opportunistic infections and cancers that are otherwise rare. Activated and differentiated CD4 cells have a pivotal role in the activation of cell-mediated and humoral immune systems [7]. HIV infection results in the depletion of CD4 cells in the peripheral blood [8]. Among untreated patients, the depletion continues over a course of several years until the patient succumbs to AIDS. It is the last stage of the HIV infection, and it presents itself anywhere between two and 15 years post-infection [9]. The following figure represents the timeline of HIV infection from the initial infection to the expression of AIDSdefining symptoms (Figure 2) [10]. 


\section{Cureus}

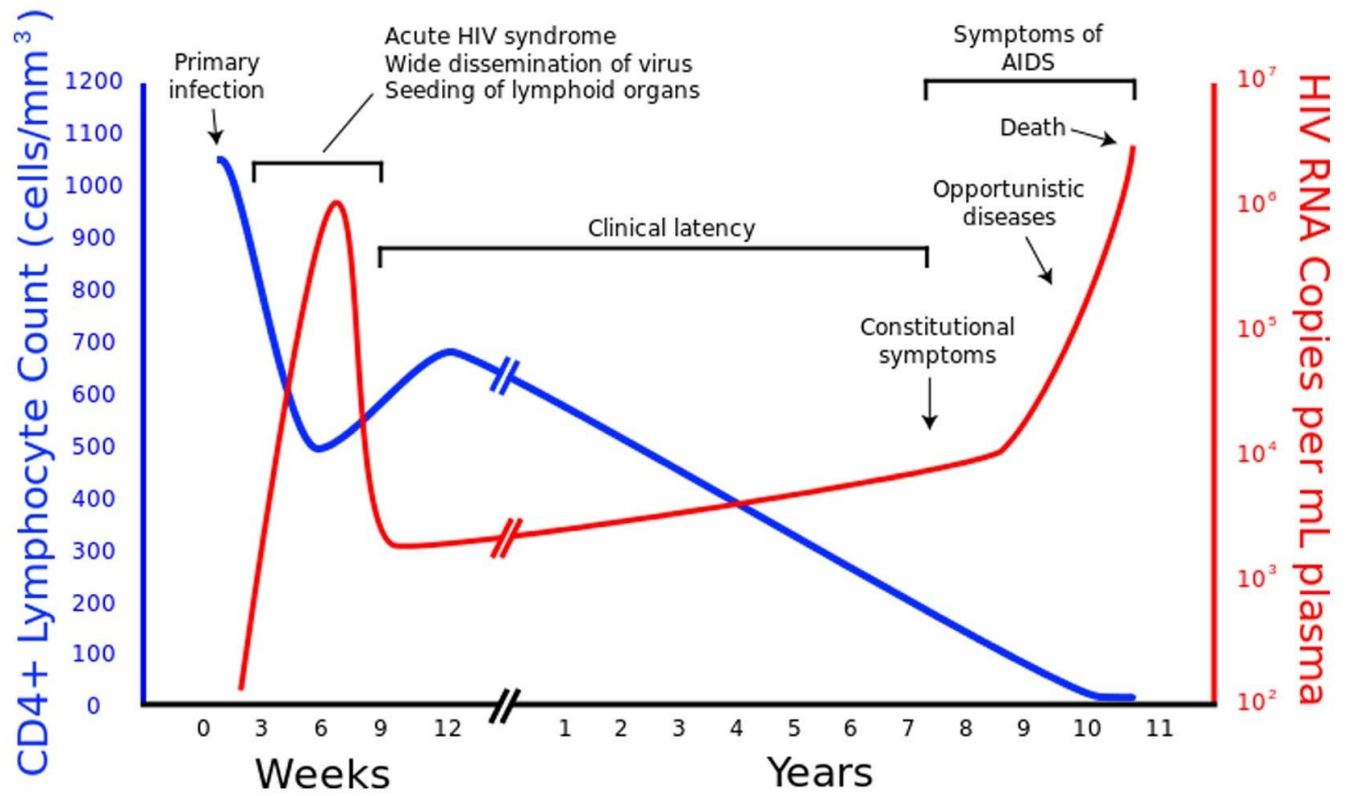

FIGURE 2: HIV time course.

Figure retrieved from Wikipedia site on December 6, 2015 from the link: https://en.wikipedia.org/wiki/HIV\#/media/File:Hiv-timecourse_copy.svg

\section{HIV subgroups}

$H I V-1$

HIV-1 is well-known for its extensive genetic diversity. There are four different lineages coming under HIV-1: M, N, O, and P. The most commonly reported HIV virus across the globe is group $\mathrm{M}$ [2]. Group N less prevalent, reported only from Cameroon [11]. Group O is accountable for 1\% of the total HIV-1 cases and is mainly found Cameroon and Gabon [12]. Group P is the rarest of all and has been identified in Cameroonian pregnant woman in France [13]. It has a prevalence of $0.06 \%$ of total HIV infections [14].

\section{$H I V-2$}

HIV-2 is most commonly reported in West Africa, with Guinea-Bissau and Senegal having the highest incidence. Eight different types of HIV-2 exist, labeled HIV-A to HIV-H. Group A is reported throughout the sub-Saharan region [15]. Group B is reported more commonly in the Ivory Coast [16]. Due to the sporadic nature of the infection and incidence, $\mathrm{C}$ to $\mathrm{H}$ are categorized as "dead-end" transmissions that produce no subsequent infections [2].

\section{Current status of HIV infection and mortality rate}

Western, Central Europe, and North America

Approximately 2.4 million individuals are HIV-positive in this region. An estimated 85,000 new HIV infections were reported in 2014, and more than $50 \%$ of infections were from the United States of America. About 26,000 AIDS-related deaths were also reported in the same period [17]. 


\section{Cureus}

As of 2014, approximately five million individuals were previously infected in Asia and the Pacific, with as many as 340,000 new HIV infections arising that year. China, Indonesia, and India contribute to about $78 \%$ of the total new disease burden in Asia and the Pacific with about 240,000 deaths. Patients receiving ART are approximately 36\%, with 3.2 million active HIV patients having no access to ART [17].

\section{Pakistan}

In Pakistan, the index case of HIV infections was reported in 1987 [18]. As per the annual report of Pakistan National AIDS Control Program, the incidence of HIV has been increasing since first reported. According to UNAIDS, the joint United Nations program on HIV/AIDS, the total number of individuals with an active HIV infection is approximately 94,000. The prevalence rate among adults is between $<0.1 \%$ and $0.2 \%$. Currently, there are as many as 26,000 women, age 15 and older, and approximately 2,100 children, up to age 14, currently living with HIV. The total number of AIDS-related deaths in this region was 2,800 in the year 2014 [19].

\section{Treatments options for HIV}

HIV infection has a very complex pathogenesis and varies substantially in different patients. Therefore, it can easily be considered as a very host-specific infection. The specificity of pathogenesis often complicates treatment options that are currently available for HIV infection [20]. Effective management of HIV infection is possible using different combinations of available drugs. This method of treatment is collectively known as antiretroviral therapy (ART). Standard ART is comprised of a concoction of at least three medicines (termed as "highly active antiretroviral therapy" or HAART) [21]. Effective ART often helps control the multiplication of HIV in infected patients and increases the count of CD4 cells, thus, prolonging the asymptomatic phase of infection, slowing the progression of the disease, and also helps in reducing the risk of transmission. Figure 3 demonstrates the percentage of HIV patients under ART [22].

Number of people receiving ART and percentage of all people living with HIV receiving ART in low- and middle-income countries overall and by WHO region, 2013

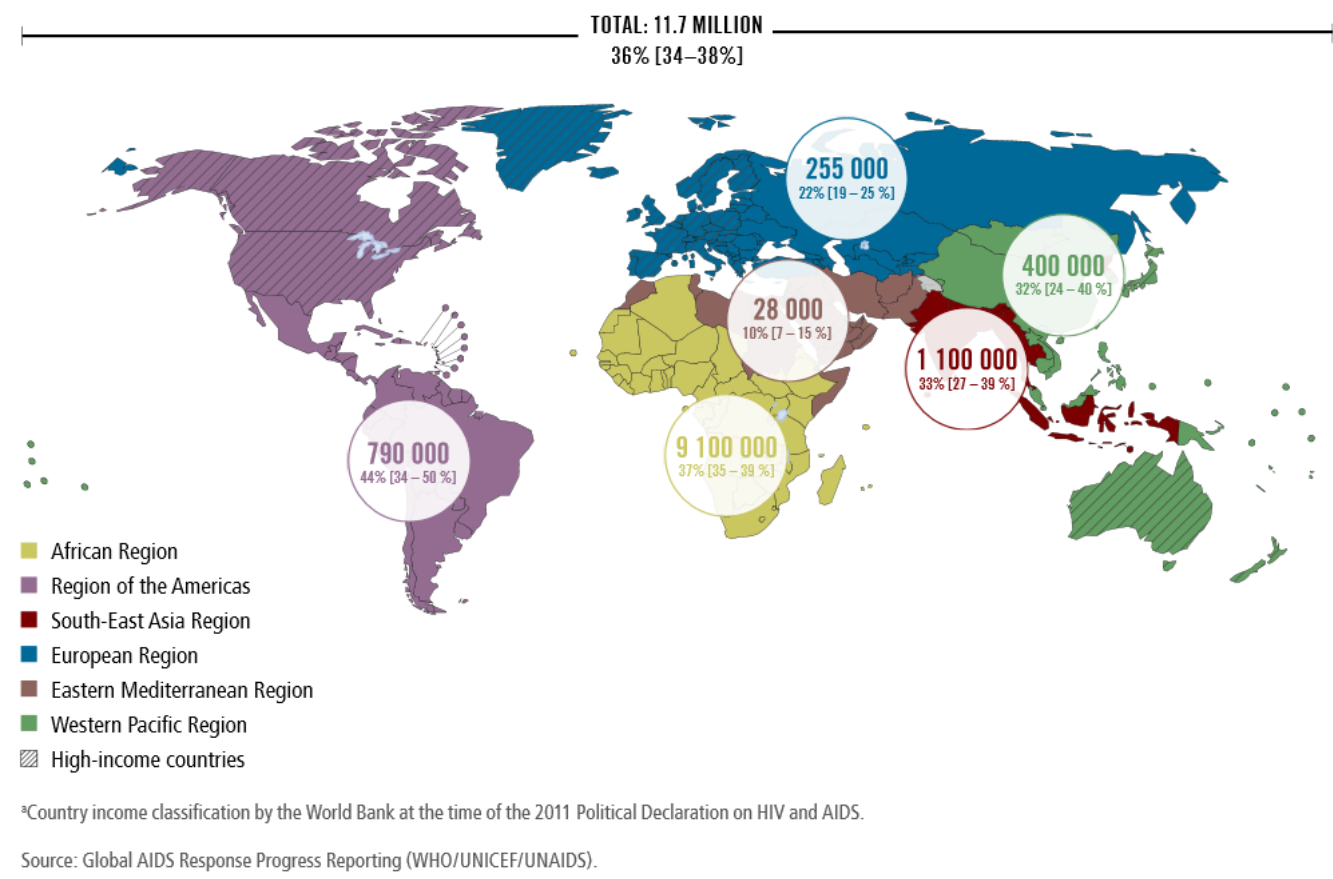




\section{FIGURE 3: Percentage of HIV patients under antiretroviral therapy (WHO 2014).}

Figure retrieved from WHO website on December 6, 2015 from the link:

http://www.who.int/hiv/data/artmap2014.png?ua=1

\section{FDA-approved HIV drug classes}

Reverse Transcriptase Inhibitors

Reverse transcriptase inhibitors are a group of drugs, which can bind and inhibit the reverse transcriptase enzyme to intercept the multiplication of HIV. There are two types of inhibitors: non-nucleoside reverse transcriptase inhibitors (NNRTIs) [23] and nucleoside reverse transcriptase inhibitors (NRTI) [24]. Examples of this group of drugs include zidovudine, didanosine, abacavir, tenofovir, and Combivir.

Protease Inhibitor

Regulation of HIV protease is of high importance for the correct assembly and production of HIV. Protease inhibitors effectively block the functioning of protease enzymes in acutely and chronically HIV-infected CD4 cells. Inhibition of HIV protease enzymes results in the liberation of immature and noninfectious viral particles [25]. Examples of this group of drugs include lopinavir/ritonavir, indinavir, ritonavir, nelfinavir, and amprenavir.

\section{Fusion Inhibitors}

This class of drugs acts by blocking HIV from entering the CD4 cells of infected patients. They inhibit the fusion of HIV particles with the CD4 cells [26]. Enfuvirtide is an example of a fusion inhibitor used in HIV treatment.

\section{Chemokine Receptor 5 Antagonist}

This group of drugs prevents the infection by blocking the chemokine receptor 5 (CCR5) antagonist receptor present on CD4 cells. In the absence of vacant CCR5 receptors, HIV fails to gain entry and infect the cell [27]. Maraviroc is an example of a CCR5 antagonist used in HIV treatment.

Integrase Strand Transfer Inhibitors

Strand transfer inhibitors prevent the integration of viral DNA into the host genome of CD4 cells by an integrase enzyme. Blocking integrase prevents HIV from replicating [28]. Raltegravir, elvitegravir, and dolutegravir are some medications in this category.

\section{Treatment regimen for HIV}

Present HIV treatment guidelines recommend ART treatment for all patients, irrespective of the CD4 cell count, to improve and prolong the progression of disease to AIDS [29]. Adherence to treatment is of paramount importance in order to achieve the full efficacy of treatment and also to prevent the incidence of drug resistance [30]. 


\section{Latest WHO recommendations for ART}

A concise form of first, second, and third line treatment options recommended by the World Health Organization (WHO) is given below [29].

First-line ART

Adults: First-line ART treatment for adults consists of two NRTIs and one NNRTI. Tenofovir disoproxil fumarate (TDF) + lamivudine (3TC) or emtricitabine (FTC) + efavirenz (EFV) as a fixed dose is the favored choice for this type of ART. When this drug combination is contraindicated or is unavailable, 1) zidovudine (AZT) + 3TC + EFV, 2) AZT + 3TC + nevirapine (NVP), or 3) TDF + 3TC (or FTC) + NVP is used.

Contraindications:

1. Creatinine clearance is less than $50 \mathrm{ml}$ per minute: Tenofovir.

2. Patients on psychoactive drug treatment: Efavirenz.

3. Patients who are pregnant or who are trying to conceive: Efavirenz.

4. ALT elevation: Nevirapine.

Pregnant and breastfeeding patients: First-line ART in this subpopulation is comprised of a single daily dose of TDF + 3TC (or FTC) + NVP. Breastfeeding infants of mothers who are receiving ART must receive six weeks of infant prophylaxis with a daily dose of NVP. The preventive medication should commence immediately post-delivery or when HIV exposure is identified.

Pediatric patients: Patients below three years of age should be given Lopinavir/Ritonavir (LPV/r)-based treatment, even under NNRTI exposure. When LPV/r is not a viable option, NVPbased treatment should be used. For infected children who are over age three, EFV is the ideal NNRTI while NVP has been identified as the second option. For infected children younger than three years of age, who develop TB while on the Lopinavir/Ritonavir (LPV/r)-based treatment, the NRTI regimen should be switched to abacavir (ABC) + 3TC or AZT + 3TC until the TB infection is cleared. NRTI regimens similar to that of adults (TDF + 3TC (or FTC)) or (AZT + 3TC) or $(\mathrm{ABC}+3 \mathrm{TC})$ are preferred for patients between 10 and 19 years of age who weigh $35 \mathrm{~kg}$ or more.

\section{Second-line ART}

Adults, including pregnant and breastfeeding patients: When a first-line treatment of ART fails, a second-line ART should be utilized. The second-line ART is comprised primarily of two NRTIs and a ritonavir-boosted PI. The recommended option for second-line ART includes AZT and 3TC as the NRTI. After the failure of AZT or stavudine $(\mathrm{d} 4 \mathrm{~T})+3 \mathrm{TC}$-based first-line regimen, TDF + 3TC (or FTC) as the NRTI should be considered. When first-line NNRTI-based treatment fails, two NRTIs + a boosted PI are suggested

Pediatric patients: For children below three years of age, first-line ART is continued even when it fails. No change in treatment is recommended; instead, adequate steps should be taken to improve adherence to the ART regimen. If first-line ART fails in children ages three and up, a second-line treatment consisting of one NNRTI and two NRTIs should be given. If ABC or TDF + 3TC (or FTC) fails, the recommended option is AZT + 3TC. After a failure of AZT or d4T + 3TC (or FTC) in first-line treatment, the preferred NRTI option is ABC or TDF + 3TC (or FTC).

Third-line ART 
If first- and second-line ART fails, the WHO recommends inclusion of new medicines with the least amount of risk for development of cross-resistance towards previously used drugs (e.g. integrase inhibitors and second-generation NNRTIs and PIs).

\title{
Factors to consider when selecting ART
}

The major factors that deserve thorough consideration while choosing an ART for a patient include the viral load and CD4 cell count before the treatment, the result of HIV genotypic drug resistance test, HLA-B*5701 status, patient preferences, and anticipated adherence. Comorbid conditions to screen prior to ART include cardiovascular disease, hyperlipidemia, renal disease, osteoporosis, psychiatric illness, neurologic disease, drug abuse or dependency requiring narcotic replacement therapy, pregnancy, coinfections with hepatitis $\mathrm{C}(\mathrm{HCV})$, hepatitis $\mathrm{B}$ (HBV), and tuberculosis (TB) [31].

\section{CD4 count monitoring for therapeutic response}

Monitoring patients' viral load is critical to identify ART response (WHO 2015). When the viral load analysis is not practical via polymerase chain reaction (PCR), branched chained DNA (bDNA), and nucleic acid sequence-based amplification (NASBA), the CD4 count is used as an indicator of HIV treatment response. During the first year of treatment, increases in CD4 count from 50 to 150 cells $/ \mathrm{mm}^{3}$ with an increased response in the first trimester are considered as a positive response. CD4 count rises steadily ranging from 50 to 100 cells $/ \mathrm{mm}^{3}$ per year until equilibrium is reached in the subsequent years (normal range: 500 cells $/ \mathrm{mm} 3$ to 1200 cells/mm3) [32]. Periodic monitoring of CD4 count is required during and even after the patient achieves normal CD4 count under ART. A number of treatment independent factors like age, viral load, genetic make-up, lifestyle, quality of health care, etc., negatively influence the CD4 counts and HIV disease progression. Under such circumstances, a change in ART medication might be required.

\section{Major factors for ART non-adherence}

\author{
Adverse Effects of ART
}

One of the major challenges that patients and physicians face with ART is the incidence of adverse drug reactions (ADR). ADR is defined as "a response to a drug that is noxious and unintended and occurs at doses normally used in man for the prophylaxis, diagnosis, or therapy of disease, or for modification of physiological function" [33]. ADR often persuades patients from continuing treatment, thus resulting in suboptimal efficacy. A serious consequence of treatment discontinuation is the emergence of drug resistance, making future therapeutic interventions ineffective [30].

The major adverse effects of ART can be grouped into the following categories:

1. Gastrointestinal: Nausea, diarrhea, vomiting, taste perversion, constipation, dyspepsia, abdominal pain, hepatotoxicity, and pancreatitis [34-35].

2. Central nervous system: Headache, vision problems, dizziness, tinnitus, insomnia, paresthesia, pain/numbness/tingling in extremities, peripheral neuropathy, somnolence, excessive sleep at night, memory problems, loss of olfactory function, and hearing impairment [34].

3. Hematological: Anemia, bilirubinemia, increased urate, and blood in the urine [35].

4. Psychological: Anxiety, confusion, depression, nightmares, elation, and delusions [35].

5. Metabolic: Abnormal fat distribution (lipodystrophy), anorexia, dyspnea, fatigue, lethargy, and weight gain [34-35]. 
6. Dermatological: Skin rash, facial discoloration, and pruritus [35].

7. Musculoskeletal: Body aches and vague chest pain [34].

8. Miscellaneous: Hypersensitive reactions, oral ulcerations, fever, and irregular menstrual cycles [34].

Drug Abuse

Continuous drug abuse is an important risk factor in HIV/AIDS patients' ART, nonadherence, and mortality [36]. In a study conducted on HIV-positive drug addicts in Canada, heroin and cocaine injections were reported to adversely affect adherence to ART [37]. In a separate sixmonth long longitudinal study, which examined the effect of drug use and abuse on ART among $150 \mathrm{HIV}$ positive patients, it was discovered that acute effects of intoxication negatively influence ART adherence. The major mechanisms by which drug abuse results in ART nonadherence include drug abuse induced neurocognitive/psychosocial impairment and psychiatric dysfunctions [38].

\section{Mental Disorders}

The prevalence of psychiatric disorders is reported to be very high among HIV-infected individuals [36]. In a longitudinal study investigating the mental health, substance abuse, and psychosocial predictors among HIV-positive mothers, the presence of psychiatric disorders, stressful lifestyles, suboptimal living conditions, and parenting stress were associated significantly with ART nonadherence [39]. Childhood sexual violence-induced anxiety and depression may also result in ART nonadherence [40]. Hazardous drinking is another significant precipitator of anxiety and depression among HIV patients that results in ART nonadherence [41].

\section{Socioeconomic Status}

Socioeconomic status is strongly associated with HIV-related mortality in the contemporary universal healthcare system because opportunities for patients of lower socioeconomic status to receive ART are meager. In a study conducted among HIV-positive Cambodian women, $80 \%$ of those who discontinued ART were of low socioeconomic status. The estimated risk for low adherence in this population was reported to be five times higher for women than those in a medium or high social position [42]. Poverty-induced stress is an important aspect that has to be addressed in issues regarding ART nonadherence [43]. The quality of housing and access to food are the two most important factors that prevent the poverty-ridden population from ART adherence [43].

\section{Poor Literacy}

Literacy is another major factor closely associated with ART nonadherence with people of lower health literacy experiencing higher illness severity than people with better health literacy [44]. Health literacy has been defined by the WHO as "the cognitive and social skills which determine the motivation and ability of individuals to gain access to, understand, and use information in ways which promote and maintain good health" [45]. Many reports suggested that the inability to comprehend medication instructions by illiterate HIV-positive patients is an important factor resulting in failure to follow accurate daily medication therapy [46].

\section{Social Stigma}

The stigma of HIV and AIDS is assumed to have a negative influence on ART 
adherence [47]. Stigma can be defined as an "attribute that is deeply discrediting" imposed by society that reduces someone "from a whole and usual person to a tainted, discounted one" [48]. In a cohort study conducted in five African countries (Lesotho, Malawi, South Africa, Swaziland, and Tanzania) among 1,457 HIV-positive patients over a period of 12 months, individuals perceiving a high HIV stigma reported greater nonadherence to ART. Symptom intensity is also high when compared to those who did not experience such a stigma [49]. One study conducted in South Africa reported that internalized stigma is responsible for $4.8 \%$ of the variance in cognitive-affective depression leading to ART nonadherence. Furthermore, the researchers urge the medical community to introduce social reform efforts to reduce stigma and assist people living with HIV/AIDS in adjusting and adapting [50].

\section{Conclusions}

Recent advances in HIV treatments have dramatically altered the nature and progression of HIV/AIDS. It can be safely considered as a "chronic" disease, provided the infected patients receive proper ART. Unfortunately, current statistics of the worldwide HIV burden tells another story: one with a steady rate of HIV-related deaths. More people die of complications and the progression of HIV to AIDS than should be when ART is used properly. The major hurdle a physician faces with ART is the incidence of adverse side effects of the treatment, which persuade patients to discontinue the treatment. Poverty, lack of awareness, and the social stigma associated with the infection complicate an already complicated situation. Appropriate changes in treatment regimens and medications can help patients overcome such adverse effects and potential complications inherent to the disease. Additionally, it is highly advisable to provide patients and their immediate family members with appropriate counseling for treatment compliance and psychological support.

\section{Additional Information \\ Disclosures}

Conflicts of interest: In compliance with the ICMJE uniform disclosure form, all authors declare the following: Payment/services info: All authors have declared that no financial support was received from any organization for the submitted work. Financial relationships: All authors have declared that they have no financial relationships at present or within the previous three years with any organizations that might have an interest in the submitted work. Other relationships: All authors have declared that there are no other relationships or activities that could appear to have influenced the submitted work.

\section{References}

1. Friedman-Kien A, Laubenstein L, Marmor M, Hymes K, Green J, Ragaz A, Gottleib J, Muggia F, Demopoulos R, Weintraub M: Kaposi's sarcoma and Pneumocystis pneumonia among homosexual men--New York City and California. MMWR Morb Mortal Wkly Rep. 1981, 30:305-308.

2. Sharp PM, Hahn BH : Origins of HIV and the AIDS pandemic . Cold Spring Harb Perspect Med. 2011, 1:a006841. Accessed: December 28, 2015:

http://perspectivesinmedicine.cshlp.org/content/1/1/a006841.full.pdf+html. 10.1101/cshperspect.a006841

3. Barin F, M'Boup S, Denis F, Kanki P, Allan JS, Lee TH, Essex M: Serological evidence for virus related to simian T-lymphotropic retrovirus III in residents of west Africa. Lancet. 1985, 2:1387-89. 10.1016/S0140-6736(85)92556-5

4. Dellar R, Karim QA: HIV/AIDS food insecurity, and undernourishment: amplifying cycles of risk in vulnerable populations. Handbook of Public Health in Natural Disasters: Nutrition, Food, Remediation and Preparation, 1st edition. Watson RR, Tabor JA, Ehiri JE, Preedy VR (ed): Wageningen Academic Publishers, Wageningen, Netherlands; 2015. 10:537-562. 10.3920/978-90-8686-806-3_31 
5. Eaton JW, Hallett TB, Garnett GP: Concurrent sexual partnerships and primary HIV infection: A critical interaction. AIDS Behav. 2011, 15:687-92. 10.1007/s10461-010-9787-8

6. WHO: Global summary of the HIV/AIDS epidemic, December 2014 . (2015). Accessed: December 6, 2015: http://www.who.int/hiv/data/epi_core_july2015.png?ua=1.

7. Luckheeram RV, Zhou R, Verma AD, Xia B: CD4+T cells: Differentiation and functions. Clin Dev Immunol. 2012, 2012 :925135. Accessed: December 28, 2015: http://www.hindawi.com/journals/jir/2012/925135/cta/. 10.1155/2012/925135

8. Brenchley JM, Schacker TW, Ruff LE, Price DA, Taylor JH, Beilman GJ, Nguyen PL, Khoruts A, Larson M, Haase AT, Douek DC: CD4+ T cell depletion during all stages of HIV disease occurs predominantly in the gastrointestinal tract. J Exp Med. 2004, 200:749-59. 10.1084/jem.20040874

9. Moss AR, Bacchetti P, Osmond D, Krampf W, Chaisson RE, Stites D, Wilber J, Allain JP, Carlson J: Seropositivity for HIV and the development of AIDS or AIDS related condition: three year follow up of the San Francisco General Hospital cohort. Br Med J (Clin Res Ed). 1988, 296:745-50. 10.1136/bmj.296.6624.745

10. HIV/AIDS. (2015). Accessed: December 6, 2015: https://en.wikipedia.org/wiki/HIV/AIDS.

11. Vallari A, Bodelle P, Ngansop C, Makamche F, Ndembi N, Mbanya D, Kaptué L, Gürtler LG, McArthur CP, Devare SG, Brennan CA.: Four new HIV-1 group N isolates from Cameroon: Prevalence continues to be low. AIDS Res Hum Retroviruses. 2010, 26:109-15. 10.1089/aid.2009.0178

12. Peeters M, Gueye A, Mboup S, Bibollet-Ruche F, Ekaza E, Mulanga C, Ouedrago R, Gandji R, Mpele P, Dibanga G, Koumare B, Saidou M, Esu-Williams E, Lombart JP, Badombena W, Luo N, Vanden Haesevelde M, Delaporte E: Geographical distribution of HIV-1 group O viruses in Africa. AIDS. 1997, 11:493-98. 10.1097/00002030-199704000-00013

13. Plantier JC, Leoz M, Dickerson JE, De Oliveira F, Cordonnier F, Lemée V, Damond F, Robertson DL, Simon F: A new human immunodeficiency virus derived from gorillas . Nat Med. 2009, 15:871-72. 10.1038/nm.2016

14. Vallari A, Holzmayer V, Harris B, Yamaguchi J, Ngansop C, Makamche F, Mbanya D, Kaptué L, Ndembi N, Gürtler L, Devare S, Brennan CA: Confirmation of putative HIV-1 group P in Cameroon. J Virol. 2011, 85:1403-1407. 10.1128/JVI.02005-10

15. de Silva TI, Cotten M, Rowland-Jones SL: HIV- 2: The forgotten AIDS virus. Trends Microbiol. 2008, 16:588-95. 10.1016/j.tim.2008.09.003

16. Ishikawa K, Janssens W, Banor JS, Shinno T, Piedade J, Sata T, Ampofo WK, Brandful JA, Koyanagi Y, Yamamoto N, Canas-Ferreira WF, Adu-Sarkodie Y, Kurata T: Genetic analysis of HIV type 2 from Ghana and Guinea-Bissau, West Africa. AIDS Res Hum Retroviruses. 2001, 17:1661-63. 10.1089/088922201753342077

17. UNAIDS: Fact sheet 2015. (2015). Accessed: December 28, 2015: http://www.unaids.org/en/resources/documents/2015/20150714_factsheet.

18. Khanani RM, Hafeez A, Rab SM, Rasheed S: Human immunodeficiency virus-associated disorders in Pakistan. AIDS Res Hum Retroviruses. 1988, 4:149-54. 10.1089/aid.1988.4.149

19. UNAIDS: Pakistan. (2014). Accessed: December 28, 2015: http://www.unaids.org/en/regionscountries/countries/pakistan.

20. Brass AL, Dykxhoorn DM, Benita Y, Yan N, Engelman A, Xavier RJ, Lieberman J, Elledge SJ: Identification of host proteins required for HIV infection through a functional genomic screen. Science. 2008, 319:921-26. 10.1126/science.1152725

21. WHO: Antiretroviral therapy. (2015). Accessed: December 28, 2015: http://www.who.int/topics/antiretroviral_therapy/en/.

22. Number of people receiving antiviral therapy (ART) and percentage of all people living with HIV receiving ART in low- and middle-income countries overall and by WHO region, 2013. (2013). Accessed: December 28, 2015: http://www.who.int/hiv/data/artmap2014.png?ua=1.

23. de Béthune MP: Non-nucleoside reverse transcriptase inhibitors (NNRTIs), their discovery, development, and use in the treatment of HIV-1 infection: a review of the last 20 years (19892009). Antiviral Res. 2010, 85:75-90. 10.1016/j.antiviral.2009.09.008

24. Whitcomb JM, Parkin NT, Chappey C, Hellmann NS, Petropoulos CJ: Broad nucleoside reverse-transcriptase inhibitor cross-resistance in human immunodeficiency virus type 1 clinical isolates. J Infect Dis. 2003, 188:992-1000. 10.1086/378281

25. Hughes PJ, Cretton-Scott E, Teague A, Wensel TM: Protease inhibitors for patients with HIV1 infection: A comparative overview. P T. 2011, 36:332-45. 
26. Greenberg ML, Cammack N: Resistance to enfuvirtide, the first HIV fusion inhibitor. J Antimicrob Chemother. 2004, 54:333-40. 10.1093/jac/dkh330

27. Rao PKS: CCR5 inhibitors: Emerging promising HIV therapeutic strategy . Indian J Sex Transm Dis. 2009, 30:1-9. 10.4103/0253-7184.55471

28. Pandey KK, Grandgenett DP: HIV-1 Integrase strand transfer inhibitors: Novel insights into their mechanism of action. Retrovirology (Auckl). 2008, 2:11-16.

29. WHO:Guideline on when to start antiretroviral therapy and on pre-exposure prophylaxis for HIV. (2015). Accessed: December 28, 2015: http://www.who.int/hiv/pub/guidelines/earlyrelease-arv/en/.

30. Olem D, Sharp KM, Taylor JM, Johnson MO: Overcoming barriers to HIV treatment adherence: A brief cognitive behavioral intervention for HIV-positive adults on antiretroviral treatment. Cogn Behav Pract. 2014, 21:206-23. 10.1016/j.cbpra.2013.09.003

31. AIDS Info: Clinical guidelines Portal. Guidelines for the use of antiretroviral agents in HIV-1infected adults and adolescents. (2015). Accessed: December 6, 2015:

http://aidsinfo.nih.gov/guidelines.

32. Kaufmann GR, Perrin L, Pantaleo G, Opravil M, Furrer H, Telenti A, Hirschel B, Ledergerber B, Vernazza P, Bernasconi E, Rickenbach M, Egger M, Battegay M; Swiss HIV Cohort Study Group: CD4 T-lymphocyte recovery in individuals with advanced HIV-1 infection receiving potent antiretroviral therapy for 4 years: the Swiss HIV Cohort Study. Arch Intern Med. 2003, 163:2187-95. 10.1001/archinte.163.18.2187

33. WHO: International drug monitoring: The role of national centers. Report of a WHO meeting . (1972). Accessed: December 28, 2015: http://apps.who.int/iris/bitstream/10665/40968/1/WHO_TRS_498.pdf.

34. Nagpal M, Tayal V, Kumar S, Gupta U: Adverse drug reactions to antiretroviral therapy in AIDS patients at a tertiary care hospital in India: A prospective observational study. Indian J Med Sci. 2010, 64:245-52. 10.4103/0019-5359.99597

35. Tadesse WT, Mekonnen AB, Tesfaye WH, Tadesse YT: Self-reported adverse drug reactions and their influence on highly active antiretroviral therapy in HIV infected patients: a cross sectional study. BMC Pharmacol Toxicol. 2014, 15:32. Accessed: December 28, 2015: http://bmcpharmacoltoxicol.biomedcentral.com/articles/10.1186/2050-6511-15-32. 10.1186/2050-6511-15-32

36. Ingersoll K: The impact of psychiatric symptoms, drug use, and medication regimen on nonadherence to HIV treatment. AIDS Care. 2004, 16:199-211. 10.1080/09540120410001641048

37. Azar P, Wood E, Nguyen P, Luma M, Montaner J, Kerr T, Milloy MJ: Drug use patterns associated with risk of non-adherence to antiretroviral therapy among HIV-positive illicit drug users in a Canadian setting: a longitudinal analysis. BMC Infect Dis. 2015, 15:193. Accessed: December 28, 2015: http://bmcinfectdis.biomedcentral.com/articles/10.1186/s12879-015-0913-0. 10.1186/s12879015-0913-0

38. Chang L, Ernst T, Speck O, Patel H, DeSilva M, Leonido-Yee M, Miller EN: Perfusion MRI and computerized cognitive test abnormalities in abstinent methamphetamine users. Psychiatry Res. 2002, 114:65-79. 10.1016/S0925-4927(02)00004-5

39. Mellins CA, Kang E, Leu CS, Havens JF, Chesney MA: Longitudinal study of mental health and psychosocial predictors of medical treatment adherence in mothers living with HIV disease. AIDS Patient Care STDS. 2003, 17:407-16. 10.1089/108729103322277420

40. Willie TC, Overstreet NM, Sullivan TP, Sikkema KJ, Hansen NB: Barriers to HIV medication adherence: Examining distinct anxiety and depression symptoms among women living with HIV who experienced childhood sexual abuse. Behav Med. 2016, 42:120-27. 10.1080/08964289.2015.1045823

41. Garey L, Bakhshaie J, Sharp C, Neighbors C, Zvolensky MJ, Gonzalez A: Anxiety, depression, and HIV symptoms among persons living with HIV/AIDS: the role of hazardous drinking. AIDS Care. 2015, 27:80-85. 10.1080/09540121.2014.956042

42. Arrivillaga M, Ross M, Useche B, Alzate ML, Correa D: Social position, gender role, and treatment adherence among Colombian women living with HIV/AIDS: social determinants of health approach. Rev Panam Salud Publica. 2009, 26:502-10. 10.1590/S102049892009001200005

43. Kalichman SC, Grebler T: Stress and poverty predictors of treatment adherence among people with low-literacy living with HIV/AIDS. Psychosom Med. 2010, 72:810-16. 


\section{Cureus}

\subsection{7/PSY.0b013e3181f01be3}

44. Kalichman SC, Rompa D: Functional health literacy is associated with health status and health-related knowledge in people living with HIV-AIDS. J Acquir Immune Defic Syndr. 2000, 25:337-44. 10.1097/00042560-200012010-00007

45. Nutbeam D: Health promotion glossary. Health Promotion International. 1998, 13:349-64.

46. Waldrop-Valverde D, Jones DL, Weiss S, Kumar M, Metsch L: The effects of low literacy and cognitive impairment on medication adherence in HIV-positive injecting drug users. AIDS Care. 2008, 20:1202-10. 10.1080/09540120801927017

47. Rintamaki LS, Davis TC, Skripkauskas S, Bennett CL, Wolf MS: Social stigma concerns and HIV medication adherence. AIDS Patient Care STDS. 2006, 20:359-68. 10.1089/apc.2006.20.359

48. Goffman E: Stigma and social identity. Stigma: Notes on the Management of Spoiled Identity. Goffman E (ed): Simon and Schuster, New York; 1963. 1-40.

49. Dlamini PS, Wantland D, Makoae LN, Chirwa M, Kohi TW, Greeff M, Naidoo J, Mullan J, Uys LR, Holzemer WL: HIV stigma and missed medications in HIV-positive people in five African countries. AIDS Patient Care STDS. 2009, 23:377-87. 10.1089/apc.2008.0164

50. Simbayi LC, Kalichman S, Strebel A, Cloete A, Henda N, Mqeketo A: Internalized stigma, discrimination, and depression among men and women living with HIV/AIDS in Cape Town, South Africa. Soc Sci Med. 2007, 64:1823-31. 10.1016/j.socscimed.2007.01.006 